\title{
WHO Europe evidence based recommendations on the treatment of tobacco dependence
}

\author{
M Raw, P Anderson, A Batra, G Dubois, P Harrington, A Hirsch, J Le Houezec, \\ A McNeill, D Milner, M Poetschke Langer, W Zatonski-Recommendations panel
}

Tobacco Control 2002;11:44-46

The following recommendations on the treatment of tobacco dependence have been written as an initiative of the World Health Organization European Partnership Project to Reduce Tobacco Dependence.

$\mathrm{T}$ his was a three year project, funded largely by three pharmaceutical companies that manufacture treatment products for tobacco dependence, but managed by WHO Europe and a steering group which included government representatives and many public sector organisations. The project focused on five areas: tracking smokers' behaviour and intention to change; the regulation of tobacco products and tobacco dependence treatment products; smoke free places and workplace policies; the implementation of evidence based treatment; and communicating the health messages about stopping smoking. These recommendations were written as part of the activities in support of evidence based treatment, and are one of a number of outputs available from the project (see www.who.dk/tobacco/home.html).

They were commissioned by the World Health Organization and have drawn on the experience of a number of European countries, including the four original target countries of the partnership project: France, Germany, Poland, and the UK. They were discussed in two European WHO meetings on evidence based treatment, in London in November 1999 and in Barcelona in October 2000, and revised in the light of feedback following those meetings. They also take into account feedback from a wide variety of individuals and organisations, including the 25 professional associations that have endorsed them to date.

It is recognised that individual countries will translate and adapt these recommendations to suit their own terminologies and healthcare systems, but it is hoped that throughout this process countries will stay as close as possible to the evidence base.

See end of article for authors' affiliations

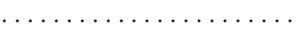

Correspondence to: Martin Raw, 11 King William IV Gardens, London SE20 7EG, UK martin@rawdata.demon.co.uk

\section{UPDATING THESE RECOMMENDATIONS}

As these are evidence based recommendations and this is a rapidly developing field, they will need periodic updating. Comments are thus welcome, as are organisations that would like to add their name to the list of endorsers. New endorsers will be added to the document posted on the web. The recommendations can be found on the WHO (www.who.dk/tobacco) and ASH (www.ash. org.uk) sites.

\section{PROFESSIONAL ENDORSEMENT}

At the time of going to press the following organisations have endorsed these guidelines: ASH England, ASH Scotland, Alliance pour la santé; coalition contre le tabagisme (France), British Medical Association, Comité National Contre le Tabagisme (CNCT), Comité Nacional de Prevención del Tabaquismo (Spain), Czech Medical Association, Danish Medical Association, Dentistry against Tobacco (Sweden), European Medical Association on Smoking or Health (EMASH), European Nurses and Midwives Against Tobacco, The European Review Group on Prevention and Health Promotion in Family Medicine and General Practice (EUROPREV), Europharm Forum, Georgian Medical Association, German Coalition against Smoking, German Medical Association, German Scientific Society for Smoking Cessation, German Society for Addiction Research and Therapy, German Society for Nicotine Research, Norwegian Medical Association, Slovenian Medical Association, Society for Research on Nicotine and Tobacco (SRNT) Europe, Swedish Medical Association, Quit (UK), World Self-Medication Industry. The latest endorsement was received on 15 November 2001.

\section{TERMINOLOGY}

Tobacco dependence treatment includes ( singly or in combination) behavioural and pharmacological interventions such as brief advice and counselling, intensive support, and administration of pharmaceuticals, that contribute to reducing or overcoming tobacco dependence in individuals and in the population as a whole. A smoking cessation specialist is someone trained and paid to deliver skilled support to smokers who need help in stopping, over and above brief opportunistic advice. They need not be medically trained but should not be offering this support unpaid and squeezed into their normal work, as the evidence suggests this is not effective.

\section{WHY THESE RECOMMENDATIONS ARE TIMELY}

Tobacco dependence is recognised as a condition in the WHO's International classification of diseases (ICD-10 $)^{1}$ and the American Psychiatric Association's Diagnostic and statistical manual, fourth edition (DSM-IV). ${ }^{2}$ In Europe millions of smokers want to stop smoking and many have tried to do so but have difficulty succeeding because tobacco use is such a powerful addiction. ${ }^{3}$ Although the majority of cessation attempts are unaided, the success rate of these unaided attempts is low. 
Smoking is a chronically relapsing condition, and even in the general population of smokers trying to stop, the relapse rate is high. The natural population cessation rate, measured over a long period in the UK, where the tobacco control movement is long established, is only about $2 \%$ each year. ${ }^{3}$

Tobacco use is recognised as a major cause of lung cancer, cardiovascular disease, and chronic obstructive lung disease (including bronchitis and emphysema), and causes 1200000 deaths each year in WHO's European region (14\% of all deaths). Unless more is done to help the 200 million European adult smokers stop, the result will be 2000000 European deaths a year by $2020 .^{4}$

Support and treatment to help smokers stop is one of a range of approaches to tobacco control. It is an issue not just for individual health professionals in their work with smokers, but for the entire healthcare system. It complements other approaches (like policies to tax tobacco products, restrictions on their use and advertising, regulation of their contents and labelling, public information, and education) but addresses a specific group: those who want to stop and need help. ${ }^{5}$ However, it is acknowledged that education remains crucially important in informing smokers about the dangers of smoking and motivating them to stop, and in many countries health education campaigns are conducted by the health care system. Furthermore, preventive approaches with young people, if effective, prevent disease 30-50 years in the future, whereas smoking cessation in current adult smokers brings population health gain more quickly, over 20-30 years. ${ }^{6}$

However, support and treatment to help smokers stop is not yet widely available. It is generally not integrated into European healthcare systems, although some countries are now making a start. Paradoxically, in contrast to the restricted availability of help for smokers in stopping (including pharmaceutical products designed to alleviate tobacco withdrawal), the tobacco products whose use causes the enormous burden of death and disease described above are extremely widely available.

\section{PURPOSE OF THESE RECOMMENDATIONS}

These recommendations propose the core interventions that should be integrated into healthcare systems, interventions that have been shown to work by a large and consistent international body of evidence. The recommendations are deliberately brief and general, rather than comprehensive, and detail should be sought from the reviews and guidelines they draw on (see below). This is because there is such a diversity of social and healthcare systems throughout Europe, including different regulatory and pharmaceutical treatment product licensing regimes. We hope each country will use these core evidence based recommendations as a skeleton on which they will add their own country specific detail. Because the recommendations are brief, they need to be read bearing in mind the context set out in this introduction. They also cover the roles of individual health professionals working to help and treat smokers as well as the roles of the wider healthcare system. This is important as public health impact will be a result not only of individual clinical effectiveness but also of coverage hence the importance of engaging the entire system locally, nationally and internationally.

\section{SCIENTIFIC BASIS AND REVIEW PROCESS}

These recommendations reflect a global movement towards evidence based medicine, and reflect the fact that an increasing number of countries are adopting evidence based guidelines for the treatment of tobacco dependence. A number of authoritative reviews and guidelines have been used as the basis for these recommendations: US Department of Health and Human Services Public Health Service Clinical Practice Guideline Treating tobacco use and dependence, 20007 ${ }^{7}$ Conclusions: smoking cessation methods, National Institute of Public Health and Swedish Council on Technology Assessment in Health Care, Sweden, 1998'; Conclusions and recommendations of the consensus conference, France, 1999'; Smoking cessation guidelines for health professionals: an update, UK, 2000 ${ }^{10}$; and the Cochrane Library systematic reviews. ${ }^{11}$ These reviews and guidelines draw on hundreds of well controlled trials, and emphasise not only that treatment for tobacco dependence is effective, but also that it is extremely cost effective: Guidance for commissioners on the cost effectiveness of smoking cessation interventions, England, 1998 ${ }^{12}$; Curbing the epidemic. Governments and the economics of tobacco control, $1999 .{ }^{13}$

These WHO recommendations are complemented by a WHO report on the regulation of tobacco dependence treatment products, which emerged from a meeting held in Helsinki in October 1999. The Helsinki report notes the contrast between the easy availability of tobacco products and tobacco dependence treatment products, which are much harder to obtain, and urges the development of regulatory approaches which will redress this imbalance. ${ }^{5}$

The evidence supports the development of three main types of intervention for health care systems: brief opportunistic interventions delivered by health professionals in the course of their routine work; more intensive support delivered by treatment specialists, often in what have been called "smokers clinics"; and pharmacological aids, which approximately double cessation in minimal or more intensive settings. The principal aids in the last category are nicotine replacement therapy (NRT) and bupropion, which is now widely available in Europe. NRT can be found on prescription, over-the-counter, and on general sale in Europe. Bupropion is a prescription only medicine.

Although the evidence base is stronger for some health professionals than others, the involvement of health professionals in offering smokers help should be based on factors such as their access to smokers and level of training and skill, rather than professional discipline. Thus the recommendations for health professionals are relevant for all health professionals and not only those based in primary care. The essential features of individual smoking cessation advice have been described as the four As: ask (about smoking at every opportunity); advise (all smokers to stop); assist (the smoker to stop); arrange (follow up). ${ }^{14}$ The updated US guideline has introduced a new A in between advise and assist: assess willingness to stop. ${ }^{7}$

It is hoped that periodically, as new evidence becomes available, as well as experience gained from the implementation of these recommendations, they will be revised and updated.

\section{Recommendations \\ 1) Recommendations for brief interventions}

As part of their normal clinical work, health professionals should provide brief interventions including the following essential features:

Ask about and record smoking status, keep record up to date Advise smokers of the benefit of stopping in a personalised and appropriate manner (this may include linking the advice to their clinical condition)

Assess motivation to stop

Assist smokers in their stop attempt if possible; this might include the offer of support, recommendation to use NRT or bupropion and accurate information and advice about them, referral to a specialist cessation service if necessary

Arrange follow up if possible.

If help can be offered a few key points can be covered in a few minutes:

- set a stop day and stop completely on that day

- review past experience and learn from it (what helped? what hindered?) 
- make a personalised action plan

- identify likely problems and plan how to cope with them

- ask family and friends for support.

Smoking and smoking cessation should be part of the core curriculum of the basic training of all health professionals.

\section{2) Recommendations for smoking cessation specialists}

The health care system should offer treatment as back up to brief opportunistic interventions for those smokers who need more intensive support. This support can be offered individually or in groups, and should include coping skills training and social support. A well tested group format includes around five sessions of about one hour over about one month with follow up. Intensive support should include the offer of or encouragement to use NRT or bupropion (as appropriate) and clear advice and instruction on how to use them.

\section{3) Pharmacotherapies}

At the moment the principal aids in this category are NRT and bupropion. There are currently six NRT products: patch, gum, nasal spray, inhalator, tablet, lozenge. Smokers of 10 or more cigarettes a day who are ready to stop should be encouraged to use NRT or bupropion as a cessation aid. Health professionals who deliver smoking cessation interventions should give smokers accurate information and advice on these products. In Europe NRT can be found on prescription, over-the-counter, and on general sale. Bupropion is a prescription only medicine and on current evidence should remain so. Evidence on the effectiveness of bupropion is currently limited to medium to heavy smokers receiving behavioural support.

\section{4) Recommendations for specific groups}

Treatment research has tended to focus on health professionals such as doctors (especially in primary care), nurses, midwives, pharmacists, and smoking cessation specialists. However, advising and supporting smokers in stopping is an activity for the whole health care system and should, eventually, be integrated into as many settings as possible throughout the system. This includes hospital and community settings. In many countries, however, there is still a high smoking prevalence among health professionals, so in addition to the education and training recommended below, health professionals should where appropriate be targeted for help in stopping smoking.

Hospital staff should ask about patients' smoking status before or on admission, and offer brief advice and assistance to those interested in stopping. Patients should be advised of the hospital's smoke free status before admission. Hospital patients who need it should also be offered NRT or bupropion.

Healthcare premises and their immediate surroundings should be smoke free.

Pregnant smokers should receive clear and accurate information on the risks of smoking to the fetus, and be advised to stop smoking. They should be offered specialist support to stop.

Cessation interventions shown to be effective with adults should be considered for use with young people, with the content modified as necessary.

\section{5) Recommendations for health care purchasers and systems}

Purchasing treatment for tobacco dependence represents an extremely cost effective way of reducing ill health and prolonging life. Health care purchasers should purchase tobacco dependence treatments, choosing a blend of interventions relevant to local circumstances but emphasising those interventions which have the strongest evidence base.

Because tobacco dependence treatment is so cost effective, it should be provided by public and private health care systems. Access to both behavioural and pharmaceutical treatments should be as wide as possible with due regard to local regulatory frameworks and other circumstances. Mechanisms should be found to increase the availability of treatment to low income smokers, including at a reduced cost or free of charge.

Health professionals should be trained to advise and help smokers stop smoking, and health care purchasers should ensure the provision of adequate training budgets and training programmes. Education and training for the different types of interventions should be provided not only at the postgraduate and clinical level, but should start at undergraduate and basic level, in medical and nursing schools and other relevant training institutions.

Telephone helplines can be effective and are very popular with smokers. Although more research is needed on their effectiveness, they seem likely to provide a valuable service to smokers and should be made available where possible.

\section{Authors' affiliations}

M Raw, Guy's King's and St Thomas' School of Medicine, University of London, London, UK

P Anderson, Department of Primary Health Care, Oxford University,

Oxford, UK

A Batra, Department of Psychiatry and Psychotherapy, University of Tübingen, Germany

G Dubois, Medical School of Amiens, France; French National

Committee against Smoking

P Harrington, WHO European Partnership Project to Reduce Tobacco

Dependence, WHO Regional Office for Europe, Copenhagen, Denmark

A Hirsch, Alliance pour la Santé; coalition contre le tabagisme, Paris,

France

J Le Houezec, R\&D Consumer Healthcare, Pharmacia; SRNT Europe,

Rennes, France

A McNeill, St George's Hospital Medical School, University of London, London, UK

D Milner, Department of Health, London, UK

M Poetschke Langer, Cancer Prevention Unit, Deutsches

Krebsforschungszentrum, Heidelberg, Germany

W Zatonski, Department of Cancer Epidemiology and Prevention, $M$

Skodowska-Curie Memorial Cancer Centre and Institute of Oncology,

Warsaw, Poland

\section{REFERENCES}

1 World Health Organization. International statistical classification of diseases and related health problems, 10th revision. Geneva: WHO, 1992

2 American Psychiatric Association. Diagnostic and statistical manual of mental disorders, 4th edition (DSM-IV). Washington DC: American Psychiatric Association, 1995.

3 Tobacco Advisory Group, Royal College of Physicians. Nicotine addiction in Britain. London: Royal College of Physicians, 2000.

4 World Health Organization Europe. Partnership to reduce tobacco dependence. Copenhagen: WHO, 2000

5 World Health Organization. Conclusions of conference on the regulation of tobacco dependence treatment products. Copenhagen: WHO, 1999.

6 Peto R, Lopez A. Future worldwide health effects of current smoking patterns. In: Koop CE, Pearson CE, Schwarz MR, eds. Critical issues in global health. San Francisco: Jossey-Bass, 2000

7 Fiore MC, Bailey WC, Cohen SJ, et al. Treating tobacco use and dependence. Clinical Practice Guideline. Rockville, US Department of Health and Human Services, 2000.

8 SBU Board of Directors and Scientific Advisory Committee Conclusions: smoking cessation methods. Stockholm: National Institute of Public Health and Swedish Council on Technology Assessment in Health Care, 1998.

9 Agence Nationale d'Accreditation et d'Evaluation en Sante. Consensus conference on smoking cessation; English summary by Jacques Le Houezec. Paris: ANAES, 1999.

10 West R, McNeill A, Raw M. Smoking cessation guidelines for health professionals: an update. Thorax 2000;55:987-99.

11 Lancaster T, Stead L, Silagy C, et al. Effectiveness of interventions to help people stop smoking: findings from the Cochrane Library. BW 2000;321:355-8

12 Parrott S, Godfrey C, Raw M, et al. Guidance for commissioners on the cost-effectiveness of smoking cessation interventions. Thorax 1998;53(suppl 5, part 2).

13 World Bank. Curbing the epidemic. Governments and the economics of tobacco control. Washington DC: World Bank, 1999.

14 Glynn TJ, Manley MW. How to help your patients stop smoking. A National Cancer Institute manual for physicians. Washington DC: US Department of Health and Human Services, 1989. 